\title{
Detection of Urine Metabolites in a Rat Model of Chronic Fatigue Syndrome before and after Exercise
}

\author{
Changzhuan Shao, ${ }^{1}$ Yiming Ren,, Zinan Wang, ${ }^{2}$ Chenzhe Kang, \\ Hongke Jiang, ${ }^{1}$ and Aiping $\mathrm{Chi}^{2}$ \\ ${ }^{1}$ College of Arts and Sciences, Shanghai Maritime University, Shanghai 201306, China \\ ${ }^{2}$ Laboratory of Nutrition and Hygiene, Shaanxi Normal University, Xian 710119, China \\ ${ }^{3}$ School of Sports, Hebei Normal University, Shijiazhuang 050090, China \\ Correspondence should be addressed to Aiping Chi; 381686871@qq.com
}

Received 17 November 2016; Accepted 5 March 2017; Published 22 March 2017

Academic Editor: Isabelle Chevalot

Copyright (C) 2017 Changzhuan Shao et al. This is an open access article distributed under the Creative Commons Attribution License, which permits unrestricted use, distribution, and reproduction in any medium, provided the original work is properly cited.

Purpose. The aim of the present study was to elucidate the metabolic mechanisms associated with chronic fatigue syndrome (CFS) via an analysis of urine metabolites prior to and following exercise in a rat model. Methods. A rat model of CFS was established using restraint-stress, forced exercise, and crowded and noisy environments over a period of 4 weeks. Behavioral experiments were conducted in order to evaluate the model. Urine metabolites were analyzed via gas chromatography-mass spectrometry (GC-MS) in combination with multivariate statistical analysis before and after exercise. Results. A total of 20 metabolites were detected in CFS rats before and after exercise. Three metabolic pathways (TCA cycle; alanine, aspartate, and glutamate metabolism; steroid hormone biosynthesis) were significantly impacted before and after exercise, while sphingolipid metabolism alone exhibited significant alterations after exercise only. Conclusion. In addition to metabolic disturbances involving some energy substances, alterations in steroid hormone biosynthesis and sphingolipid metabolism were detected in CFS rats. Sphingosine and 21-hydroxypregnenolone may be key biomarkers of CFS, potentially offering evidence in support of immune dysfunction and hypothalamic-pituitary-adrenal (HPA) axis hypoactivity in patients with CFS.

\section{Introduction}

Chronic fatigue syndrome (CFS) is a debilitating illness associated with serious changes in physical, mental, and occupational well-being and, frequently, social isolation, with a prevalence of $0.2-2.6 \%$ and $1.9-3 \%$ in Western countries and China, respectively [1-5]. The typical presentation of CFS is characterized by sudden onset of a flu-like illness in which the predominant symptom is severe and lasting fatigue that greatly reduces activity [6].

Several hypotheses have been proposed for the pathogenesis of CFS including oxidative stress, hypothalamicpituitary-adrenal (HPA) axis abnormalities, and immune dysfunction [7-9]. The US Centers for Disease Control and Prevention (CDC) offer a clinical definition of CFS based on the Holmes and Fukuda scoring and evaluation systems [2]. However, the identification of diagnostic markers for
CFS remains challenging. The discovery of such biomarkers may have been impeded by the fact that the unique biologic changes responsible for production of the original illness may no longer be present in most patients with CFS [4]. However, one consistently observed finding across patients with CFS is the exacerbation of symptoms following exercise (postexertional malaise). Therefore, the CDC symptom inventory differentiates patients with CFS from those without the syndrome according to the occurrence of postexertional malaise [10]. Thus, identification of specific biological changes associated with postexertional malaise offers a promising approach for the discovery of biomarkers of CFS.

Metabonomics focuses on all known and unknown molecular compounds rather than the analysis of individual metabolites alone, allowing new insight into the metabolic status of the entire body [11]. Specifically, an analysis of 
metabolite profiles before and after exercise may aid in the detection of metabolic changes associated with CFS. One of the most useful approaches for diagnosis as well as biomarker identification involves metabolite profiling of biological samples using combined gas chromatography-mass spectrometry (GC-MS) [12].

In the present study, we established a rat model of CFS using restraint-stress, forced exercise, and crowded/noisy environments. GC-MS in combination with multivariate statistical analysis was employed to evaluate changes in the metabolic profiles of urine specimens in order to identify potential biomarkers and investigate metabolic mechanisms underlying the development of CFS.

\section{Methods}

2.1. Establishment of the CFS Model. Twenty female SpragueDawley rats (weight: $200 \pm 20$ g, 5-6 weeks old) were obtained from the Experimental Animal Centre of Xian Jiaotong University (license number: SCXK (Shaan) 2012-003) in Xi'an, China. The animals were randomly allocated to either a control group or a CFS group, with 10 rats in each group. All animals were housed in a temperature-controlled environment $\left(23 \pm 2^{\circ} \mathrm{C}\right)$ with a humidity of $55 \% \pm 15 \%$ under a $12 \mathrm{~h}$ light-dark cycle, with free access to water and standard rodent chow. All animal experiments were performed in accordance with the National Institutes of Health (NIH) Guidelines for the Care and Use of Laboratory Animals. The Animal Ethics Committee of Xian Jiaotong University (Xi'an China) reviewed and approved the entire animal protocol prior to conducting the experiments.

Based on the findings of previous reports [13-15], four methods (restraint-stress, forced exercise, and crowded and noisy environments) were adopted to mimic the multiplefactor pathogenesis of CFS. Rats in the CFS group were exposed to these conditions for 4 weeks. For restraint-stress, rats were fixed individually in a polyvinyl chloride tube $(20.0 \mathrm{~cm}$ in length, $5.0 \mathrm{~cm}$ in diameter) for $4 \mathrm{~h}$. For forced exercise, the rats were forced to run on a treadmill $(20 \mathrm{~m} / \mathrm{min})$ for $1 \mathrm{~h}$. The 10 rats in the CFS group were housed together in a standard rearing cage (crowded environment), whereas those in the control group were housed in individual cages. Rats of the CFS group were also exposed to rock music for $12 \mathrm{~h}$ each day (noisy environment). The protocol of the CFS model is shown in Figure S1, in Supplementary Material available online at https://doi.org/10.1155/2017/8182020.

2.2. Behavioral Evaluation of the CFS Model. After 4 weeks, the body weights and dietary intakes of the rats were recorded. The Morris-water-maze test, open-field test, and tail-suspension test were performed to evaluate the CFS model, as in our previous study [16]. The Morris-water-maze test was performed using a Morris-water-maze instrument (Beijing Shidi-Chuangke Co., Ltd. China). Briefly, the pool was divided into four quadrants, and a circular escape platform (12 cm in diameter) was submerged $2 \mathrm{~cm}$ below the surface of the water in the 2 nd quadrant. The rats were trained to locate and mount the escape platform when placed in the other three quadrants. After 4 days of training, the time spent searching for the escape platform was calculated for each rat. The escape platform was then removed, and the number of times that the rats passed the previous location of the platform in $1 \mathrm{~min}$ was recorded.

The open-field test was conducted using an open-field behavior detector (ZH-ZFT, Huaibei Zhenghua Biological Instrument Equipment Co., Ltd., Anhui Province, China) with nine grids. An animal behavior videotracking system was used to record the locomotion of each rat. Each rat was placed in the middle grid, and the number of times that the rat crossed through the adjacent grids within 3 minutes was recorded, along with the number of times the rat stood on its hind legs. For the tail-suspension test, the tails of the rats were fixed on a horizontal board ( $1 \mathrm{~m}$ in height from the ground), and the time the rats spent motionless over a duration of 6 min was recorded.

2.3. Urine Sample Preparation. Urine samples were collected from all rats following behavioral evaluation (before exercise). Rats of each group were then forced to run on a treadmill $(20 \mathrm{~m} / \mathrm{min})$ for $1 \mathrm{~h}$, following which urine samples were again collected (after exercise). Each sample was treated with $0.1 \mathrm{~mL}$ of $1 \%$ sodium azide solution and stored at $-80^{\circ} \mathrm{C}$ until measurement.

2.4. GC-MS Analysis of Urine Samples. The urine samples were thawed at room temperature, and $100 \mu \mathrm{L}$ of urine sample was transferred to a $1.5 \mathrm{~mL}$ sample vial and diluted with purified water at a ratio of $1: 1(\mathrm{v} / \mathrm{v})$. Then, $10 \mu \mathrm{L}$ of urease suspension $(160 \mathrm{mg} / \mathrm{mL}$ in water) was added to each sample vial, and the samples were incubated at $37^{\circ} \mathrm{C}$ for $1 \mathrm{~h}$ to decompose and remove excess urea. Subsequently, $0.35 \mathrm{~mL}$ of methanol was added, and the samples were mixed with $500 \mu \mathrm{L}$ of acetonitrile. The samples were then vortexed for $30 \mathrm{~s}$ and centrifuged for $15 \mathrm{~min}$ at $4^{\circ} \mathrm{C}(12,000 \mathrm{rpm})$ to remove any particulates. Next, $400 \mu \mathrm{L}$ of supernatant was transferred to a $1.5 \mathrm{~mL}$ sample vial, dried under nitrogen, mixed with $80 \mu \mathrm{L}$ of methoxyamine pyridine solution $(20 \mathrm{mg} / \mathrm{mL})$, and incubated at $80^{\circ} \mathrm{C}$ for $20 \mathrm{~min}$. Next, $100 \mu \mathrm{L}$ of derivatization reagent (BSFTA + TMCS) was added, and the samples were sealed and incubated at $70^{\circ} \mathrm{C}$ for $1 \mathrm{~h}$. Finally, $5 \mu \mathrm{L}$ of FAMEs was added to the mixed sample, and the sample was permitted to cool to room temperature, following which it was mixed thoroughly in preparation for GC-MS analysis.

GC-MS analysis was performed using an Agilent 7890 gas chromatograph system coupled with a Pegasus HT time-offlight mass spectrometer. The system utilized an Rxi-5Sil MS column $(30 \mathrm{~m} \times 250 \mu \mathrm{m} \times 0.25 \mu \mathrm{m}$, Restek, USA $)$. A $1 \mu \mathrm{L}$ aliquot of the analyte was injected in splitless mode. Helium was used as the carrier gas. The front inlet purge flow was $3 \mathrm{~mL} / \mathrm{min}$, and the gas flow rate through the column was $20 \mathrm{~mL} / \mathrm{min}$. The initial temperature was maintained at $50^{\circ} \mathrm{C}$ for $1 \mathrm{~min}$ and then increased to $330^{\circ} \mathrm{C}$ at a rate of $10^{\circ} \mathrm{C} / \mathrm{min}$, followed by maintenance at $330^{\circ} \mathrm{C}$ for $5 \mathrm{~min}$. The injection, transfer line, and ion source temperatures were 280, 280, and $250^{\circ} \mathrm{C}$, respectively. The energy was $-70 \mathrm{eV}$ in the electron impact mode. The mass spectrometry data were acquired in full-scan mode at an $\mathrm{m} / \mathrm{z}$ range of $30-600$ at a rate of 20 spectra per second after a solvent delay of $366 \mathrm{~s}$. 
TABLE 1: Results of the behavioral tests.

\begin{tabular}{|c|c|c|c|c|c|c|c|c|}
\hline \multirow{2}{*}{$\begin{array}{l}\text { Groups } \\
(n=10)\end{array}$} & \multirow{2}{*}{$\begin{array}{c}\text { Body weight } \\
\text { (g) }\end{array}$} & \multicolumn{2}{|c|}{ Diet } & \multicolumn{2}{|c|}{ Morris-water-maze test } & \multicolumn{2}{|c|}{ Open-field test } & \multirow{2}{*}{$\begin{array}{l}\text { Tail- } \\
\text { suspension } \\
\text { test } \\
\text { Motionless } \\
\text { time(s) }\end{array}$} \\
\hline & & Fodder (g/d) & Water (mL/d) & $\begin{array}{c}\text { Time of } \\
\text { searching for } \\
\text { platform(s) }\end{array}$ & $\begin{array}{l}\text { Number of } \\
\text { times }\end{array}$ & $\begin{array}{l}\text { Number of } \\
\text { times }\end{array}$ & $\begin{array}{c}\text { Number of } \\
\text { standing } \\
\text { events }\end{array}$ & \\
\hline Control & $201.37 \pm 9.09$ & $20.84 \pm 4.45$ & $54.65 \pm 8.97$ & $31.22 \pm 14.53$ & $1.38 \pm 1.30$ & $46.25 \pm 5.23$ & $15.88 \pm 4.12$ & $78.75 \pm 15.37$ \\
\hline CFS & $\begin{array}{c}177.90 \pm \\
11.13^{* *}\end{array}$ & $16.61 \pm 3.15^{* *}$ & $45.89 \pm 12.45$ & $50.09 \pm 18.09^{*}$ & $0.75 \pm 0.71$ & $33.69 \pm 5.19^{* *}$ & $11.50 \pm 2.48^{*}$ & $\begin{array}{l}100.50 \pm \\
11.94^{* *}\end{array}$ \\
\hline
\end{tabular}

${ }^{*} P<0.05$ and ${ }^{* *} P<0.01$ versus the control group.

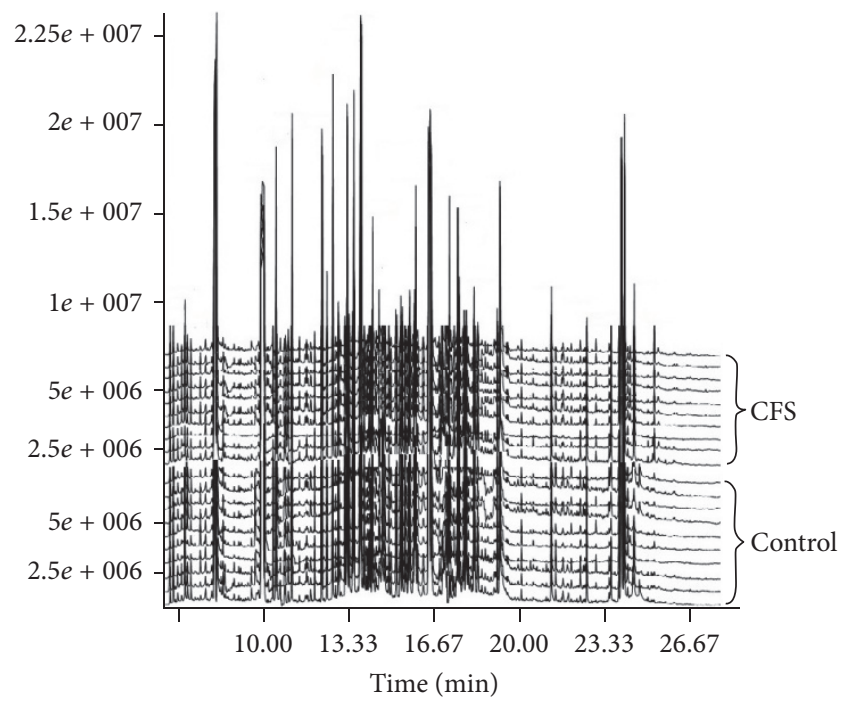

(a)

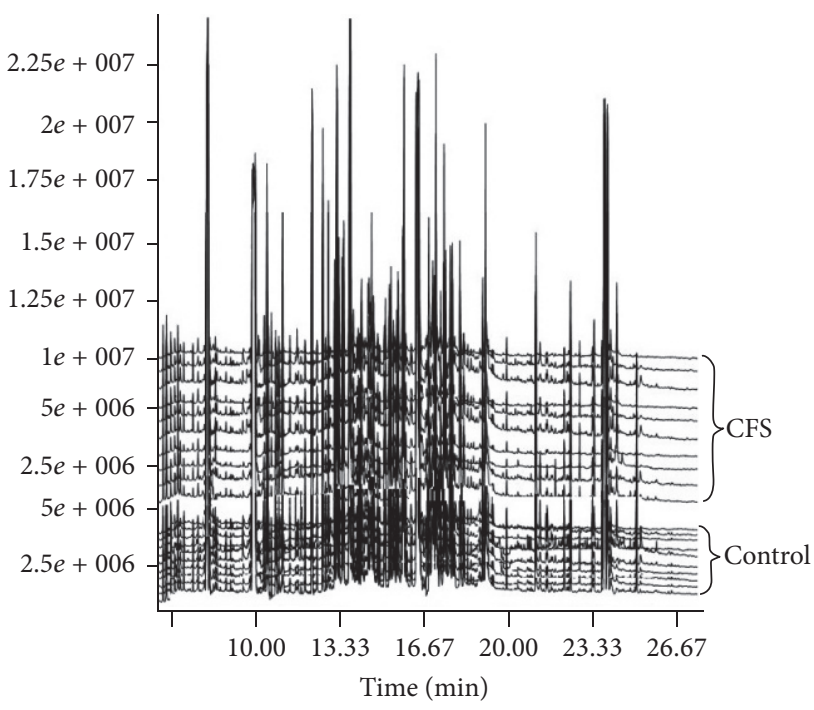

(b)

FIGURE 1: Total ion chromatograms of the urine samples obtained from the CFS and control groups. (a) Before exercise. (b) After exercise.

2.5. Statistical Analysis. The body weights, dietary intake, and behavioral performance of the rats were analyzed using SPSS software (version 17.0). The data are presented as means \pm standard deviations (SD). Differences between means were determined using independent $t$-tests. $p$ values $<0.05$ were considered statistically significant, while $p$ values $<0.01$ were considered extremely significant.

The detected peaks were aligned using manual integral methods. Peaks were analyzed only when they were consistently detected in at least $80 \%$ of the samples. All detected peaks were identified by comparing the MS spectra with those available in the Kyoto Encyclopaedia of Genes and Genomes (KEGG; http://www.genome.jp/kegg/). Only those compounds with a matching probability of greater than $70 \%$ were examined. The retention time and $\mathrm{m} / \mathrm{z}$ data pairs were used as the identifiers for each peak in each sample. Statistical analysis was performed using multivariate statistics combined with univariate statistics. Normalized data were exported to SIMCA software (Version 14.0, Umetrics $A B$, Umea, Sweden) to perform an orthogonal partial least squares discriminant analysis (OPLS-DA), and a model was built to identify the variables that accounted for the differentiation of CFS.

\section{Results}

3.1. Behavioral Analysis. As shown in Table 1, significant alterations (increases or decreases) were observed in a total of seven evaluation indexes for rats in the CFS group relative to the control group, indicating that chronic stress resulted in physical and mental fatigue in the rats and that the CFS model had been successfully established.

3.2. GC-MS Analysis of Metabolic Profiling. The stability and repeatability of the GC-MS system for large-scale sample analysis were confirmed by analysis of pooled Quality Control (QC) samples and the retention time (RT) of the internal standard. Ten QC samples and the internal standard were analyzed for urine samples throughout the entire analysis. The principal component analysis (PCA) score plot, including all the test and QC samples, revealed that the QC sample features were tightly clustered. The relative standard deviation (RSD) of the retention times in the internal standard was less than $0.49 \%$. Thus, the stability and repeatability of the proposed method were deemed acceptable. Typical total ion chromatograms (TICs) of urine samples from the control and CFS groups are presented in Figure 1. Subsequently, 


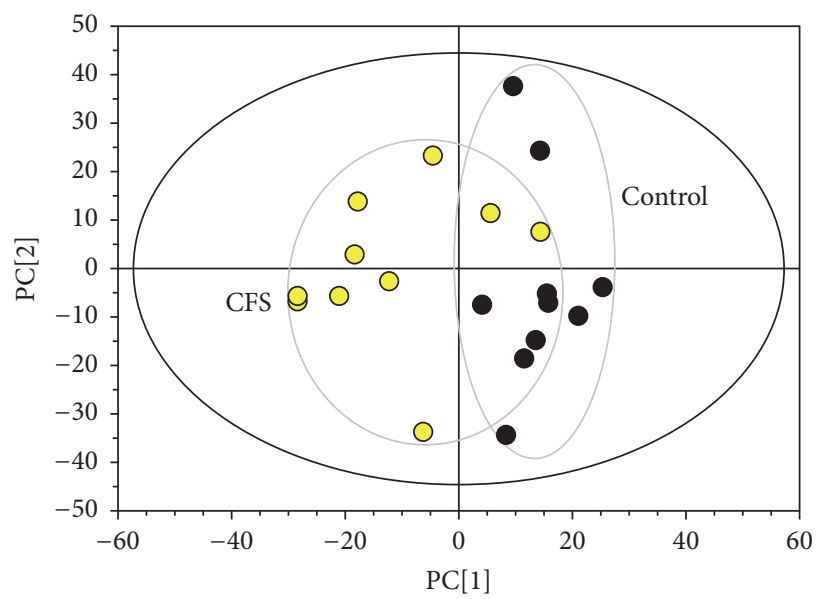

OPLS-DA
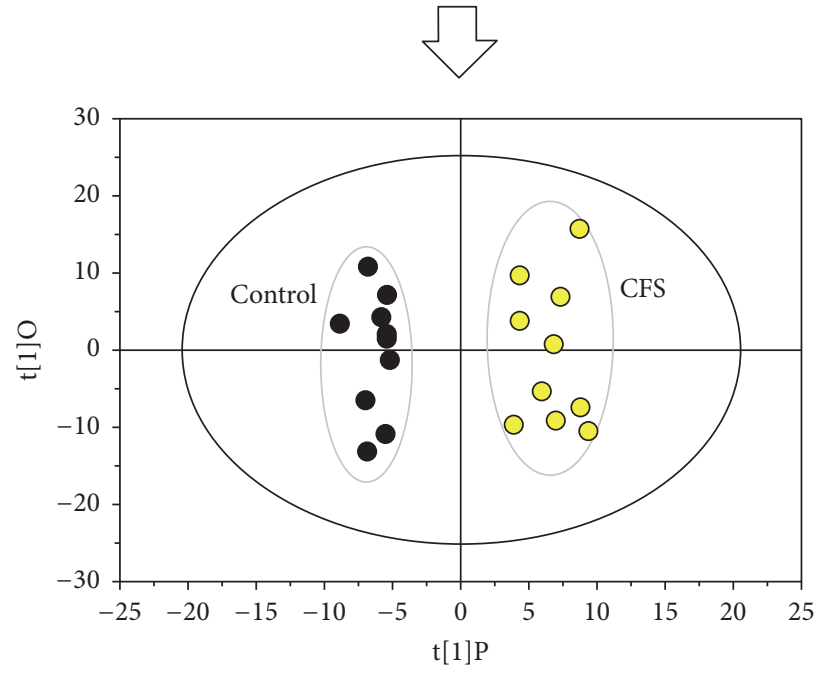

(a)

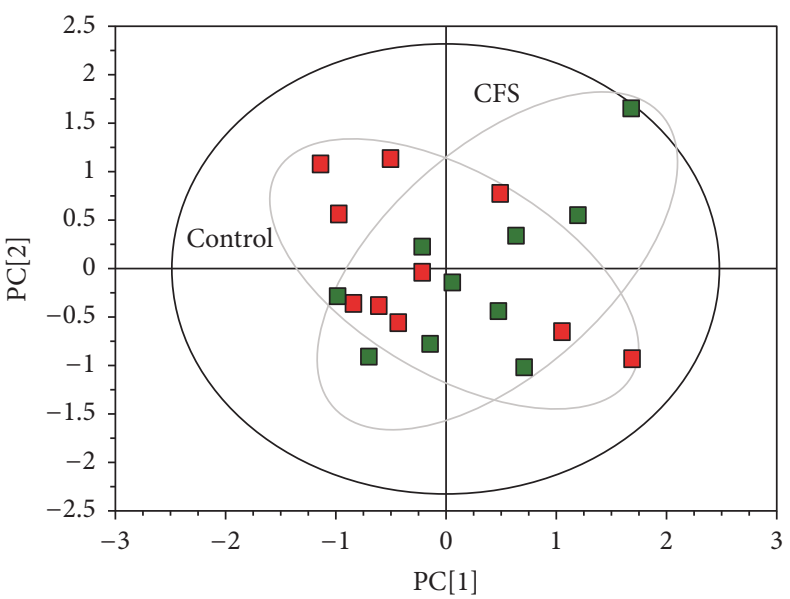

OPLS-DA

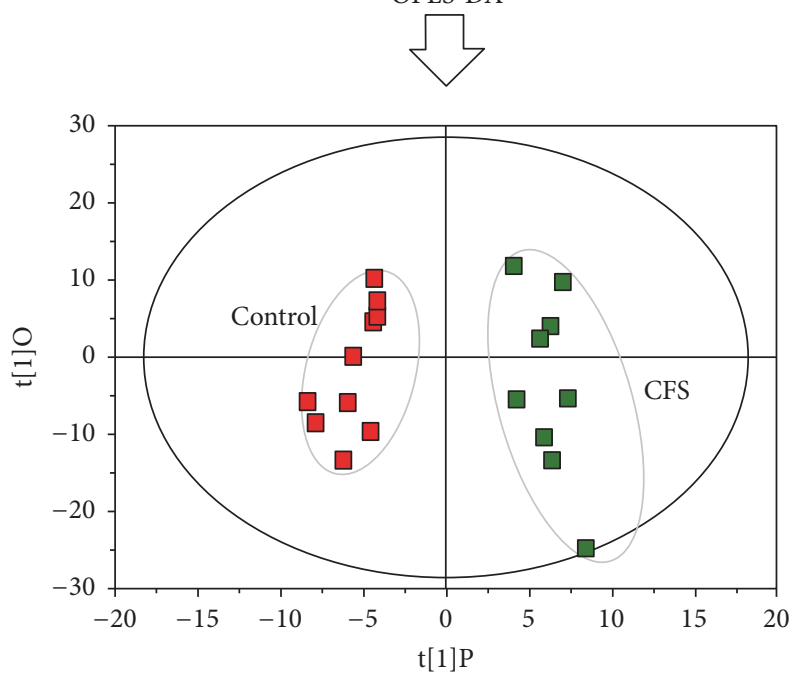

(b)

FIGURE 2: PCA scores plot and OPLS-DA scores plot of urine sample from the CFS and control groups. (a) Before exercise. (b) After exercise.

PCA was performed to obtain a comprehensive view of the metabonome, and an unsupervised multivariate data analysis was conducted to visualize the trends and outliers in the data for the control and CFS groups. As shown in Figure 2, the score plots were not clearly separated; however, the CFS group exhibited a tendency to deviate from the control group after the OPLS-DA. The model was validated using a permutation test. $R^{2} Y$ and $Q^{2}$ of the OPLS-DA model were 0.912 and 0.556 (Figure 3), respectively, indicating that the model was both reliable and predictive.

To identify the variables responsible for this large separation, the variable importance (VIP) in the projection statistics from OPLS-DA modeling and $t$-tests $(p<0.05)$ between the two groups were used to preselect variables. The GC-MS spectra of the metabolites were analyzed based on KEGG and mass spectra libraries, and metabolites were required to meet the following conditions: VIP $>1$ and $p<0.05$. As shown in Table 2, a total of 20 metabolites were identified in the CFS group before and after exercise when compared with control group. These potential biomarkers contributed to the

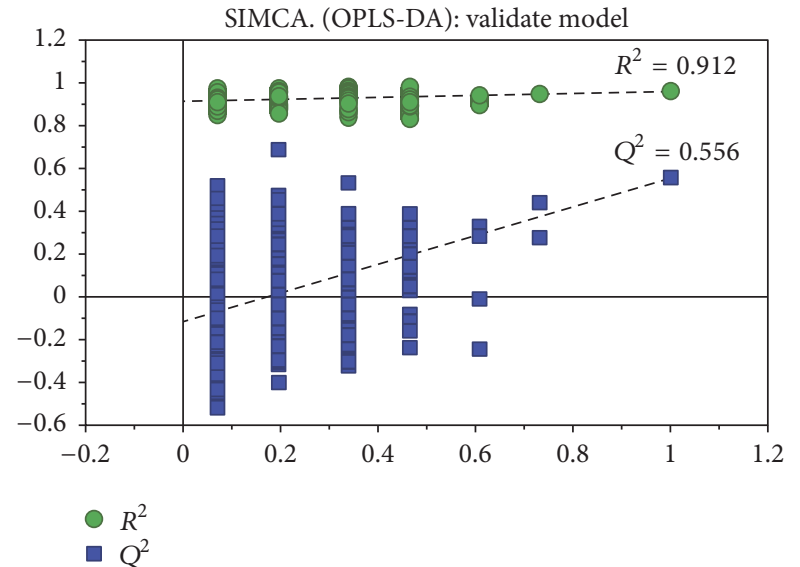

FIGURE 3: Validation of OPLS-DA model by permutation test. Validation of OPLS-DA model of rats urinary samples from two groups by permutation test (the $x$-axis means the correlation coefficient between the original $y$ variable and the permutated $y$ variable and the $y$-axis is the value of $R^{2}$ and $Q^{2}$ ). 
TABLE 2: Potential biomarkers and the related pathways in CFS group in comparison with the control group.

\begin{tabular}{|c|c|c|c|c|c|c|c|c|}
\hline & Number & RT & $m / z$ & KEGG & Formula & Metabolite & Trend $^{\mathrm{a}}$ & Related pathway \\
\hline \multirow{10}{*}{ Pre-exercise } & 1 & 8.87 & 188 & C00383 & $\mathrm{CH}_{2}\left(\mathrm{COOC}_{2} \mathrm{H}_{5}\right)_{2}$ & Malonic acid & $\downarrow^{*}$ & $\begin{array}{l}\text { Pyrimidine metabolism; } \\
\beta \text {-alanine metabolism }\end{array}$ \\
\hline & 2 & 13.64 & 247 & C01013 & $\mathrm{C}_{3} \mathrm{H}_{6} \mathrm{O}_{3}$ & $\begin{array}{l}\text { 3-Hydroxypropionic } \\
\text { acid }\end{array}$ & $\downarrow^{*}$ & $\begin{array}{l}\text { Pyrimidine metabolism; } \\
\beta \text {-alanine metabolism; } \\
\text { propanoate metabolism }\end{array}$ \\
\hline & 3 & 13.84 & 304 & C00026 & $\mathrm{C}_{5} \mathrm{H}_{7} \mathrm{NO}_{5}$ & $\alpha$-Ketoglutaric acid & $\downarrow^{* *}$ & $\begin{array}{l}\text { TCA cycle; alanine, } \\
\text { aspartate, and glutamate } \\
\text { metabolism }\end{array}$ \\
\hline & 4 & 14.21 & 164 & C05593 & $\mathrm{C}_{8} \mathrm{H}_{7} \mathrm{O}_{3}$ & $\begin{array}{l}\text { 3-Hydroxyphenylacetic } \\
\text { acid }\end{array}$ & $\downarrow^{* *}$ & $\begin{array}{c}\text { Tyrosine metabolism; } \\
\text { phenylalanine metabolism }\end{array}$ \\
\hline & 5 & 14.46 & 267 & C00156 & $\mathrm{C}_{7} \mathrm{H}_{6} \mathrm{O}_{3}$ & 4-Hydroxybenzoic acid & $\downarrow^{* *}$ & Phenylalanine metabolism \\
\hline & 6 & 18.01 & 202 & C00954 & $\mathrm{C}_{10} \mathrm{H}_{9} \mathrm{NO}_{2}$ & Indole-3-acetic acid & $\downarrow^{*}$ & Tryptophan metabolism \\
\hline & 7 & 18.24 & 319 & C00880 & $\mathrm{C}_{6} \mathrm{H}_{10} \mathrm{O}_{7}$ & Galactonic acid & $\downarrow^{*}$ & Galactose metabolism \\
\hline & 8 & 18.27 & 333 & C00257 & $\mathrm{C}_{6} \mathrm{H}_{12} \mathrm{O}_{7}$ & Gluconic acid & $\downarrow^{* *}$ & $\begin{array}{c}\text { Pentose phosphate } \\
\text { pathway; biosynthesis of } \\
\text { antibiotics }\end{array}$ \\
\hline & 9 & 23.19 & 230 & C00294 & $\mathrm{C}_{10} \mathrm{H}_{12} \mathrm{~N}_{4} \mathrm{O}_{5}$ & Inosine & $\downarrow^{*}$ & Purine metabolism \\
\hline & 10 & 26.58 & 73 & C05485 & $\mathrm{C}_{6} \mathrm{H}_{11} \mathrm{NO}_{3}$ & $\begin{array}{l}21- \\
\text { Hydroxypregnenolone }\end{array}$ & $\downarrow^{* * *}$ & $\begin{array}{c}\text { Steroid hormone } \\
\text { biosynthesis }\end{array}$ \\
\hline \multirow{10}{*}{ Post-exercise } & 1 & 8.87 & 188 & C00383 & $\mathrm{CH}_{2}\left(\mathrm{COOC}_{2} \mathrm{H}_{5}\right)_{2}$ & Malonic acid & $\downarrow^{* *}$ & $\begin{array}{l}\text { Pyrimidine metabolism; } \\
\beta \text {-alanine metabolism }\end{array}$ \\
\hline & 2 & 11.00 & 245 & $\mathrm{C} 00122$ & $\mathrm{C}_{4} \mathrm{H}_{4} \mathrm{O}_{4}$ & Fumaric acid & $\uparrow^{*}$ & $\begin{array}{l}\text { TCA cycle; alanine, } \\
\text { aspartate, and glutamate } \\
\text { metabolism }\end{array}$ \\
\hline & 3 & 11.65 & 184 & C01732 & $\mathrm{C}_{5} \mathrm{H}_{6} \mathrm{O}_{4}$ & 2-Methylfumarate & $\uparrow^{*}$ & $\begin{array}{c}\mathrm{C}_{5} \text {-branched dibasic acid } \\
\text { metabolism }\end{array}$ \\
\hline & 4 & 12.73 & 233 & C00149 & $\mathrm{C}_{4} \mathrm{H}_{6} \mathrm{O}_{5}$ & Malic acid & $\uparrow^{*}$ & TCA cycle \\
\hline & 5 & 13.83 & 304 & $\mathrm{C} 00026$ & $\mathrm{C}_{5} \mathrm{H}_{7} \mathrm{NO}_{5}$ & $\alpha$-Ketoglutaric acid & $\downarrow^{*}$ & $\begin{array}{l}\text { TCA cycle; alanine, } \\
\text { aspartate, and glutamate } \\
\text { metabolism }\end{array}$ \\
\hline & 6 & 14.48 & 292 & C00898 & $\mathrm{C}_{4} \mathrm{H}_{6} \mathrm{O}_{6}$ & Tartaric acid & $\downarrow^{* *}$ & TCA cycle \\
\hline & 7 & 18.27 & 333 & C00257 & $\mathrm{C}_{6} \mathrm{H}_{12} \mathrm{O}_{7}$ & Gluconic acid & $\downarrow^{*}$ & $\begin{array}{c}\text { Pentose phosphate } \\
\text { pathway; biosynthesis of } \\
\text { antibiotics }\end{array}$ \\
\hline & 8 & 18.77 & 117 & C00249 & $\mathrm{C}_{16} \mathrm{H}_{32} \mathrm{O}_{2}$ & Palmitic acid & $\uparrow^{*}$ & $\begin{array}{c}\text { Fatty acid metabolism; } \\
\text { biosynthesis of unsaturated } \\
\text { fatty acids }\end{array}$ \\
\hline & 9 & 22.16 & 204 & C00319 & $\mathrm{C}_{14} \mathrm{H}_{31} \mathrm{NO}_{6} \mathrm{~S}$ & Sphingosine & $\downarrow^{*}$ & Sphingolipid metabolism \\
\hline & 10 & 26.57 & 73 & C05485 & $\mathrm{C}_{6} \mathrm{H}_{11} \mathrm{NO}_{3}$ & $\begin{array}{c}21- \\
\text { Hydroxypregnenolone }\end{array}$ & $\downarrow^{* * *}$ & $\begin{array}{l}\text { Steroid hormone } \\
\text { biosynthesis }\end{array}$ \\
\hline
\end{tabular}

a $(\uparrow)$ : upregulated; $(\downarrow)$ : downregulated. ${ }^{*} p<0.05 ;{ }^{* *} p<0.01 ;{ }^{* * *} p<0.001$.

discrimination of the metabolic profiles between the CFS and control groups.

3.3. Pathway Topology Analysis. To identify possible metabolic pathways affected by CFS, the 20 identified metabolites were analyzed using MetPA (http://www.metaboanalyst.ca/). As shown in Table 3, nine (preexercise) and 14 (postexercise) metabolic pathways were generated in CFS group in comparison with the control groups, and the pathway impact values of those metabolic pathways were calculated via a pathway topology analysis with a threshold of
0.01 . The results revealed that three metabolic pathways (TCA cycle; alanine, aspartate, and glutamate metabolism; and steroid hormone biosynthesis) of the CFS rats were filtered out before and after exercise, while sphingolipid metabolism alone exhibited significant alterations after exercise only (Figure 4).

Metabolites detected before and after exercise differed in the metabolic pathways associated with the TCA cycle. As shown in Figure 5 and Table 2, $\alpha$-ketoglutaric acid was markedly decreased both before exercise $(p<0.01)$ and after 
TABLE 3: Impact scores for metabolic pathways in CFS.

\begin{tabular}{|c|c|c|c|c|c|c|c|c|c|}
\hline Time & Pathway Name & Total & Hits & $p$ & $-\log (p)$ & Holm $p$ & FDR & $\begin{array}{c}\text { Impact } \\
\text { score }\end{array}$ & $\begin{array}{c}\text { Ranking } \\
\text { list }^{*}\end{array}$ \\
\hline \multirow{9}{*}{$\begin{array}{l}\text { Before } \\
\text { exercise }\end{array}$} & TCA cycle & 20 & 1 & 0.134 & 2.008 & 1.00 & 1.00 & 0.068 & 1 \\
\hline & $\begin{array}{l}\text { Alanine, aspartate and } \\
\text { glutamate metabolism }\end{array}$ & 24 & 1 & 0.159 & 1.839 & 1.00 & 1.00 & 0.063 & 2 \\
\hline & $\begin{array}{l}\text { Steroid hormone } \\
\text { biosynthesis }\end{array}$ & 70 & 1 & 0.402 & 0.912 & 1.00 & 1.00 & 0.015 & 3 \\
\hline & Purine metabolism & 68 & 1 & 0.393 & 0.935 & 1.00 & 1.00 & 0.003 & - \\
\hline & $\begin{array}{c}\text { D-Glutamine and } \\
\text { D-glutamate metabolism }\end{array}$ & 5 & 1 & 0.035 & 3.347 & 1.00 & 1.00 & 0.000 & - \\
\hline & beta-Alanine metabolism & 19 & 1 & 0.128 & 2.056 & 1.00 & 1.00 & 0.000 & - \\
\hline & Propanoate metabolism & 20 & 1 & 0.134 & 2.008 & 1.00 & 1.00 & 0.000 & - \\
\hline & Butanoate metabolism & 20 & 1 & 0.134 & 2.008 & 1.00 & 1.00 & 0.000 & - \\
\hline & Tryptophan metabolism & 41 & 1 & 0.258 & 1.357 & 1.00 & 1.00 & 0.000 & - \\
\hline \multirow{14}{*}{ After exercise } & TCA cycle & 20 & 3 & 0.000 & 8.181 & 0.02 & 0.02 & 0.140 & 1 \\
\hline & $\begin{array}{l}\text { Alanine, aspartate, and } \\
\text { glutamate metabolism }\end{array}$ & 24 & 2 & 0.012 & 4.454 & 0.93 & 0.47 & 0.067 & 2 \\
\hline & Sphingolipid metabolism & 21 & 1 & 0.141 & 1.963 & 1.00 & 1.00 & 0.053 & 3 \\
\hline & $\begin{array}{l}\text { Steroid hormone } \\
\text { biosynthesis }\end{array}$ & 70 & 1 & 0.402 & 0.912 & 1.00 & 1.00 & 0.015 & 4 \\
\hline & $\begin{array}{c}\text { D-Glutamine and } \\
\text { D-glutamate metabolism }\end{array}$ & 5 & 1 & 0.035 & 3.347 & 1.00 & 0.95 & 0.000 & - \\
\hline & $\begin{array}{c}\text { Glyoxylate and } \\
\text { dicarboxylate metabolism }\end{array}$ & 16 & 1 & 0.109 & 2.219 & 1.00 & 1.00 & 0.000 & - \\
\hline & Butanoate metabolism & 20 & 1 & 0.134 & 2.008 & 1.00 & 1.00 & 0.000 & - \\
\hline & Pyruvate metabolism & 22 & 1 & 0.147 & 1.919 & 1.00 & 1.00 & 0.000 & - \\
\hline & $\begin{array}{l}\text { Fatty acid elongation in } \\
\text { mitochondria }\end{array}$ & 27 & 1 & 0.177 & 1.730 & 1.00 & 1.00 & 0.000 & - \\
\hline & Fatty acid metabolism & 39 & 1 & 0.247 & 1.400 & 1.00 & 1.00 & 0.000 & - \\
\hline & Tyrosine metabolism & 42 & 1 & 0.263 & 1.336 & 1.00 & 1.00 & 0.000 & - \\
\hline & $\begin{array}{l}\text { Biosynthesis of unsaturated } \\
\text { fatty acids }\end{array}$ & 42 & 1 & 0.263 & 1.336 & 1.00 & 1.00 & 0.000 & - \\
\hline & Fatty acid biosynthesis & 43 & 1 & 0.268 & 1.315 & 1.00 & 1.00 & 0.000 & - \\
\hline & $\begin{array}{l}\text { Arginine and proline } \\
\text { metabolism }\end{array}$ & 44 & 1 & 0.274 & 1.295 & 1.00 & 1.00 & 0.000 & - \\
\hline
\end{tabular}

${ }^{*}$ Threshold of the impact score $>0.01$.

exercise $(p<0.05)$, whereas fumaric acid and malic acid were increased after exercise $(p<0.05)$. In metabolic pathways associated with alanine, aspartate, and glutamate metabolism, similar changes in $\alpha$-ketoglutaric acid were observed before and after exercise, while levels of fumaric acid decreased after exercise (Figure 6). Our findings revealed that the level of 21-hydroxypregnenolone in CFS rats was significantly decreased $(p<0.001)$ in the pre- and postexercise conditions in comparison with the controls (Table 2). As shown in Figure 7, corticosterone and aldosterone were the direct and indirect downstream products based on the analysis of 21-hydroxypregnenolone metabolic pathway. In addition, increases in sphingosine were detected $(p<0.05)$ only after exercise (Figure 8). Therefore, we summarized the metabolic mechanisms of CFS according to the above results (shown in Figure 9).

\section{Discussion}

In the present study, we established a rat model of CFS over 4 weeks using four types of stimulation: restraint-stress, forced exercise, crowded environment, and noisy environment [17]. As patients with CFS typically present with behavioral symptoms such as memory deficits, inattention, disinterest in new activities, and depression [18-20], we utilized a variety of behavioral tests to assess the validity of our model. The Morris-water-maze test is often used to detect the learning and memory capabilities of animals [21]: rodents will strive to escape from water and will exploit spatial memory to exit the water as quickly as possible. The open-field test evaluates the exploration activities of the animals and their emotions in a new environment and can be used to examine their anxiety and excitability, while the tail-suspension tests 


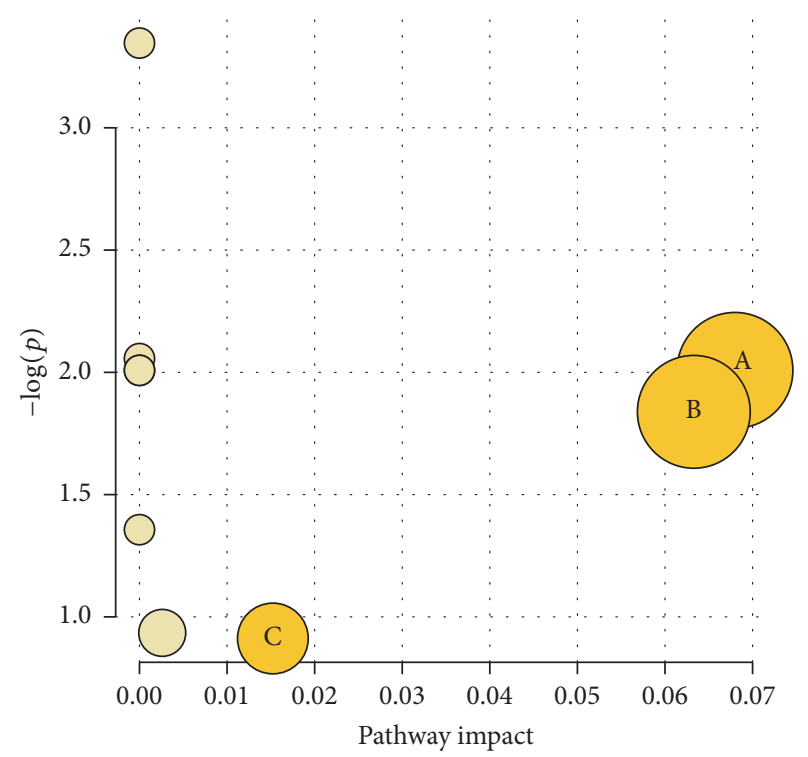

(a)

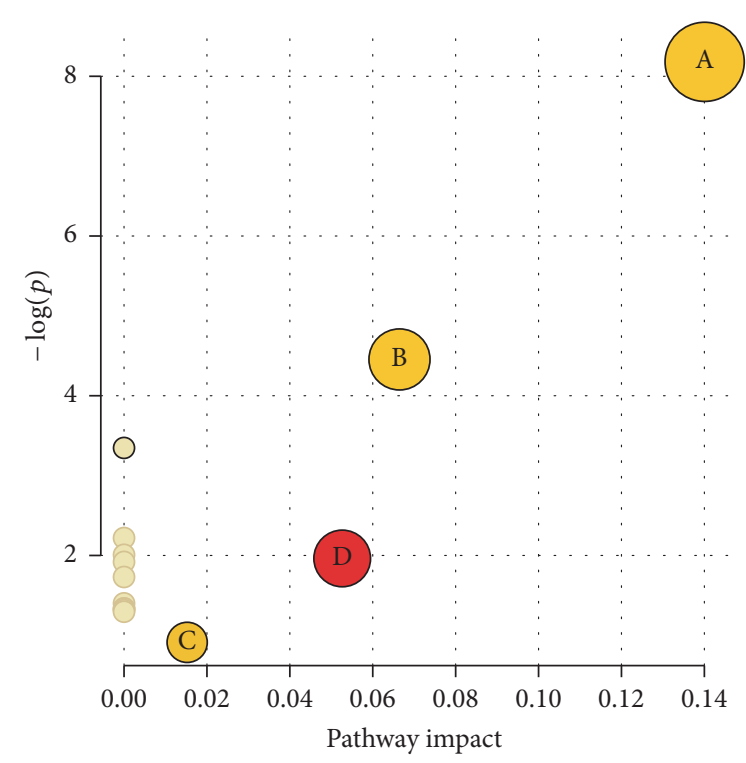

(b)

FIGURE 4: Results of the metabolic pathway topology analysis. (a) Before exercise. (b) After exercise. (A) TCA cycle. (B) Alanine, aspartate, and glutamate metabolism. (C) Steroid hormone biosynthesis. (D) Sphingolipid metabolism.

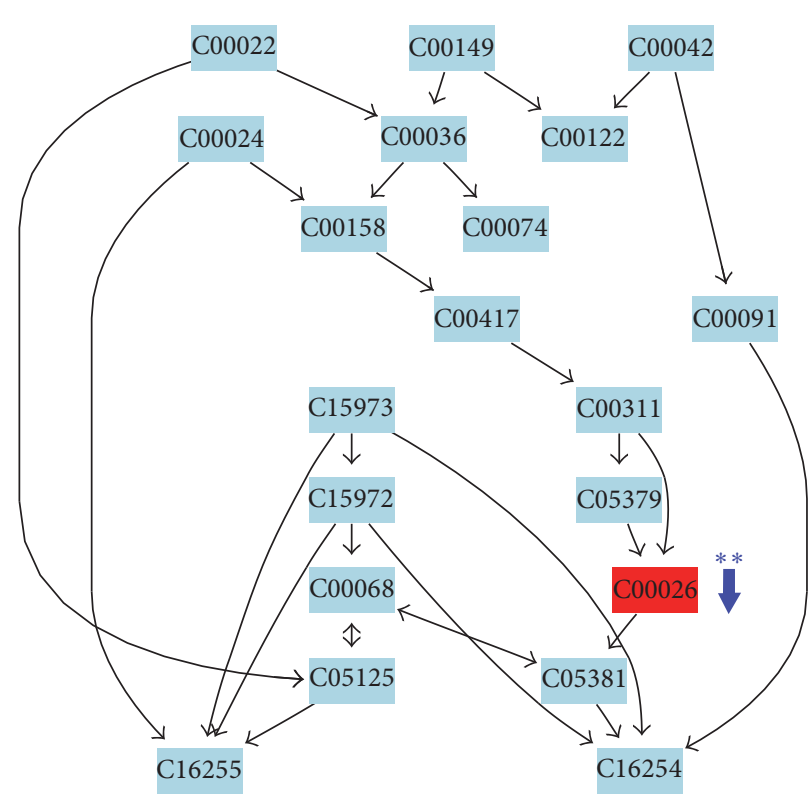

(a)

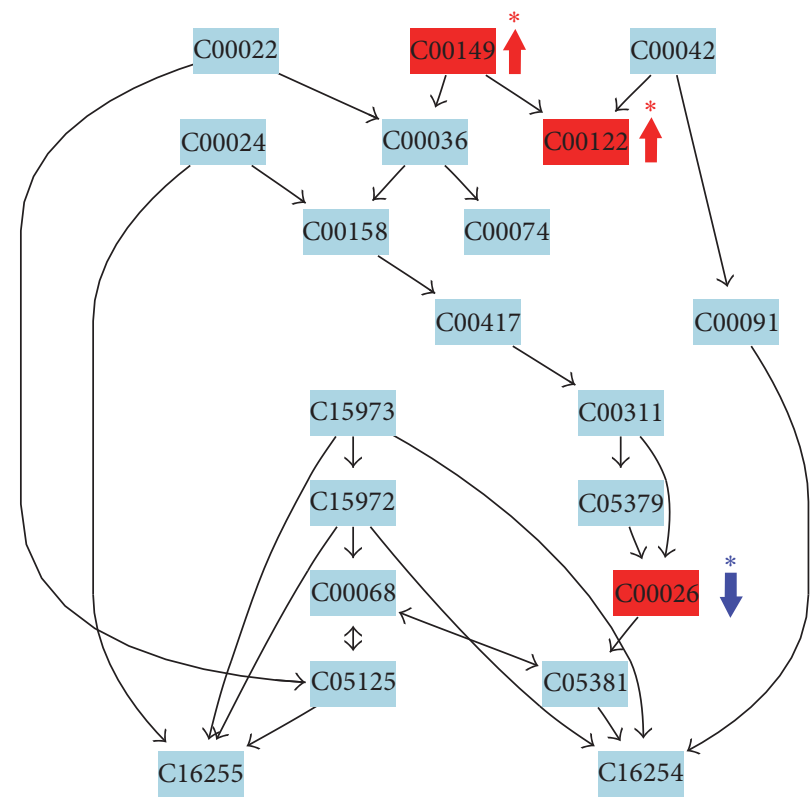

(b)

FIGURE 5: Metabolic pathway of TCA cycle. (a) Before exercise. Key metabolite: $\alpha$-ketoglutaric acid (C00026). (b) After exercise. Key metabolites: malic acid (C00149), fumaric acid (C00122), and $\alpha$-ketoglutaric acid (C00026). $\uparrow$ : upregulated, $\downarrow$ : downregulated, ${ }^{*} p<0.05$, and ${ }^{* *} p<0.01$ versus control.

reflect disappointment and depression in animals. Our results indicate that chronic stress resulted in physical and mental fatigue in the rats and that the methods used to generate the CFS model were successful. The results of our pathway topology revealed the dysfunction of the TCA cycle; alanine, aspartate, and glutamate metabolism; and steroid hormone biosynthesis in CFS rats.
The persistent fatigue and muscle weakness were the symptoms in CDC symptom inventory list that differentiated subjects with CFS from those without the syndrome [22, 23]. McCully and Natelson reported that the lactic acid level increased and the oxygen transfer ability decreased in CFS patients after exercise [24]. The blood rheology research showed there was the significant microcirculation 


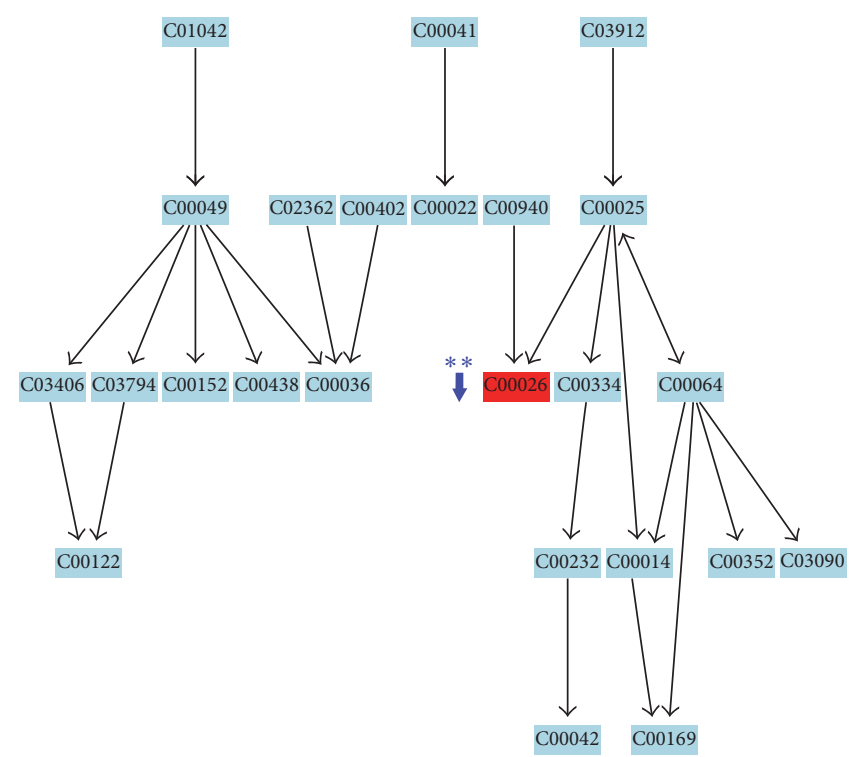

(a)

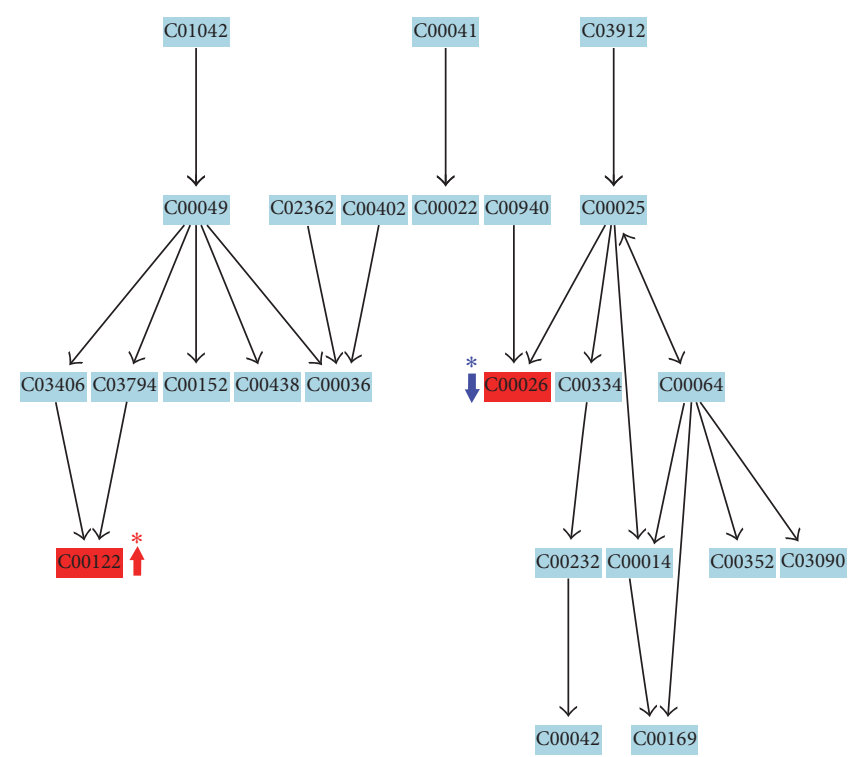

(b)

Figure 6: Metabolic pathway of alanine, aspartate, and glutamate metabolism. (a) Before exercise. Key metabolite: $\alpha$-ketoglutaric acid (C00026). (b) After exercise. Key metabolites: fumaric acid (C00122) and $\alpha$-ketoglutaric acid (C00026). $\uparrow$ : upregulated, $\downarrow$ : downregulated, ${ }^{*} p<0.05$, and ${ }^{* *} p<0.01$ versus control.

disturbance in CFS patients, which affected not only the movement of red blood cells in capillaries but also the metabolism of oxygen and lactate [25]. The disorder of the aerobic metabolism caused the lack of the energy supply in muscle contraction, which leads to body fatigue. There was close relationship between the energy metabolism and the fatigue or muscle weakness. The TCA cycle represents the intersection of the catabolism of sugar, fat, and amino acids. The intermediate metabolites of the TCA cycle are also the origins of many biosynthetic pathways. Therefore, TCA status is a comprehensive reflection of energy metabolism in the body [26]. So we concluded that dysfunction in TCA cycle metabolism could explain those fatigue symptoms in CFS.

Additionally, a number of studies have demonstrated a state of generalized immune activation and selective immune dysfunction, in patients with CFS [27, 28]. Other authors also reported that the lymphocyte proliferation function and monocytes phagocytosis decreased in CFS patients, as well as number and activity of natural killer (NK) cell $[29,30]$. The process of chronic fatigue stimulations accelerated leukocyte apoptosis and upset the balance of the immunity system in the regulation of cell metabolism [31]. In metabolites analysis, $\alpha$-ketoglutaric acid and fumaric acid were filtered (before exercise and/or after exercise) which associated with not only TCA cycle metabolism but also alanine, aspartate, and glutamate metabolism. It is well known that the alanine, aspartate, and glutamate metabolism play transfer amidogen role in amino acid metabolism, which directly or indirectly affects the formation of antibody and glutamine. The latter can improve the proliferation and differentiation of lymphocytes [32]. So we concluded that the immunity dysfunction of CFS patients associated with metabolic disturbance in the alanine, aspartate, and glutamate metabolism.
Besides the reduced learning ability, short-term memory loss, and difficulty concentrating, the cognitive biases on diseases also belong to CFS identification standard of CDC. Those CFS patients with cognitive biases think that disease is an unpredictable and uncontrollable physiological problem and then actually increase their asthenic feeling and fatigue feeling $[33,34]$. Some studies have demonstrated the potential involvement of the central and autonomic nervous system in patients with CFS $[35,36]$. In the present research, the results revealed a visible perturbation of the urine metabolic profiles in CFS rats, with steroid hormone biosynthesis identified as the key metabolic pathway associated with the mechanism underlying CFS. It is well known that 21hydroxypregnenolone plays an important role during steroid hormone biosynthesis and can improve memory, prevent fatigue, and relieve stress [37, 38]. HPA axis abnormalities have also been proposed as potential modes of CFS pathogenesis [8]. Some research has indicated that cortisol levels in patients with CFS are lower than those of healthy controls due to damage to cortical hormone markers [39]. Therefore, we inferred that 21-hydroxypregnenolone may be a biomarker of HPA axis abnormalities in patients with CFS.

Our results further suggest that sphingolipid metabolism is significantly associated with the effect of exercise on metabolic pathways in patients with CFS. It is generally known that sphingolipid is one important component of the cell membrane. And ceramide, sphingosine, and sphingosine-1-phospate, named "sphingomyelin rheostat," are the most important metabolites in sphingolipid metabolism. Some research has indicated that the unbalance of "sphingomyelin rheostat" caused the memory loss and cognitive decline in patients of Alzheimer's disease and autism $[40,41]$. Sphingosine can participate in the generation 


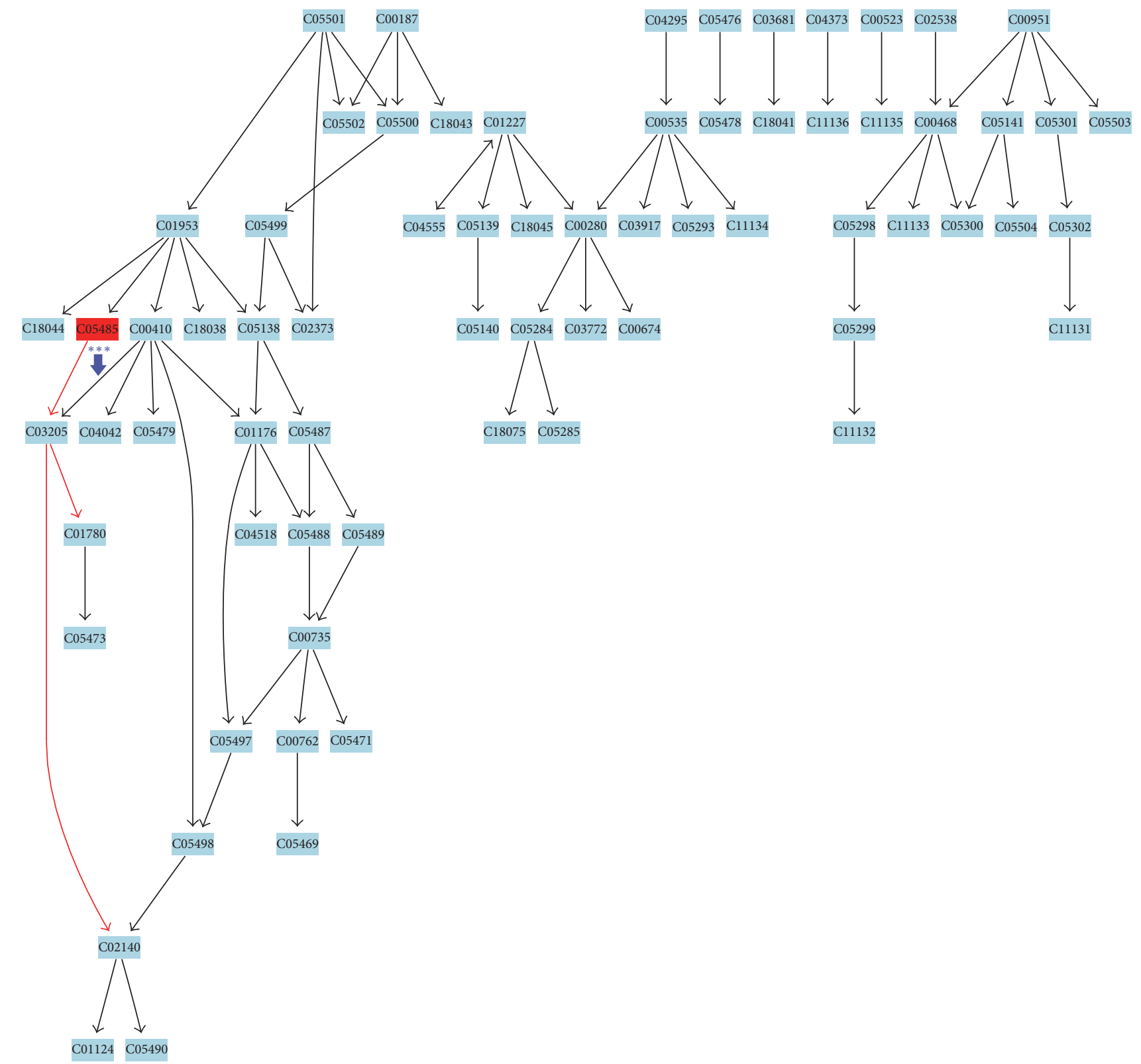

FIGURE 7: Metabolic pathway of steroid hormone biosynthesis. Related metabolites: 21-hydroxypregnenolone (C05485), deoxycorticosterone (C03205), corticosterone (C02140), and aldosterone (C01780). $\downarrow$ : downregulated and ${ }^{* * *} p<0.001$ versus control.

of ceramide during sphingomyelin metabolism and promote immune function, cognition, and learning and memory in rats $[42,43]$.

The intensive exercise can aggravate the symptoms of CFS patients [44], and then we can obtain the more physiological information from them after exercise. Our results showed that the sphingosine levels significantly decreased in CFS rats after exercise. Therefore, we regarded sphingosine as the key biomarker underlying the effects of exercise which can explains the immune dysfunction and the decline of cognition, learning, and memory (as shown in Figure 9). However, the mechanism needs further to be explored on the reduced sphingosine level because of exercise.

\section{Conclusions}

In the present study, we employed a metabonomics approach to investigate the potential underlying mechanisms of CFS. Based on the multivariate statistical analysis, three metabolic pathways and a total of six metabolites were identified in comparison with the control group. Significant alterations were specifically observed in the sphingolipid pathway following exercise. Our findings indicate that sphingosine levels following exercise may represent a novel biomarker of CFS. However, patients with CFS differ to some extent from mere animal models of the disease. Therefore, further studies involving patients with CFS are required in order to 


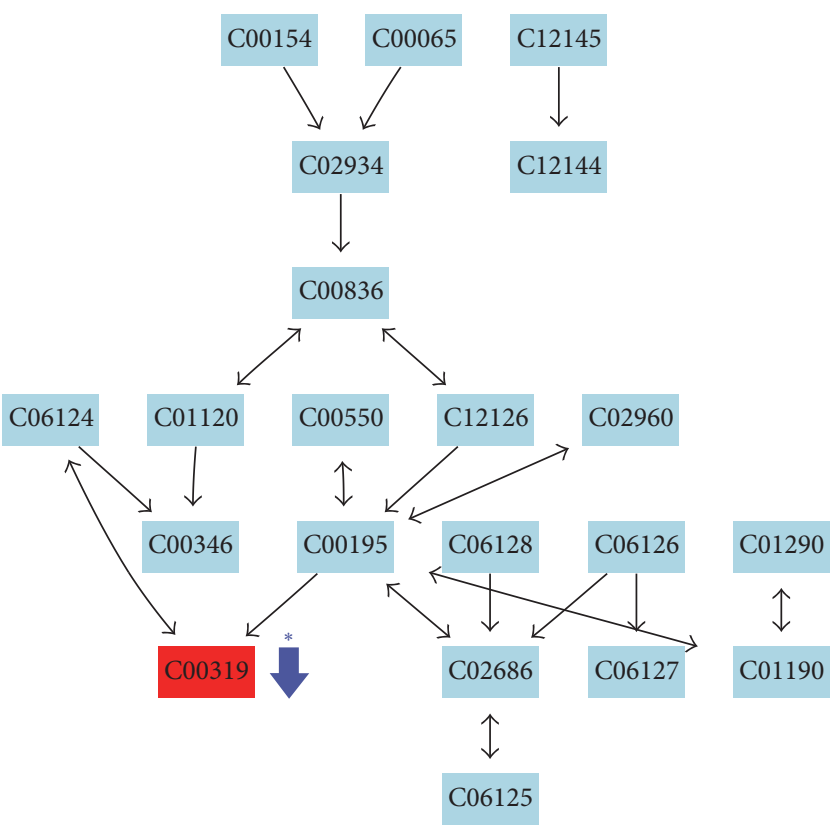

Figure 8: Metabolic pathway of sphingolipid metabolism. Key metabolites: sphingosine (C00319). $\downarrow$ : downregulated and ${ }^{*} p<0.05$ versus control.

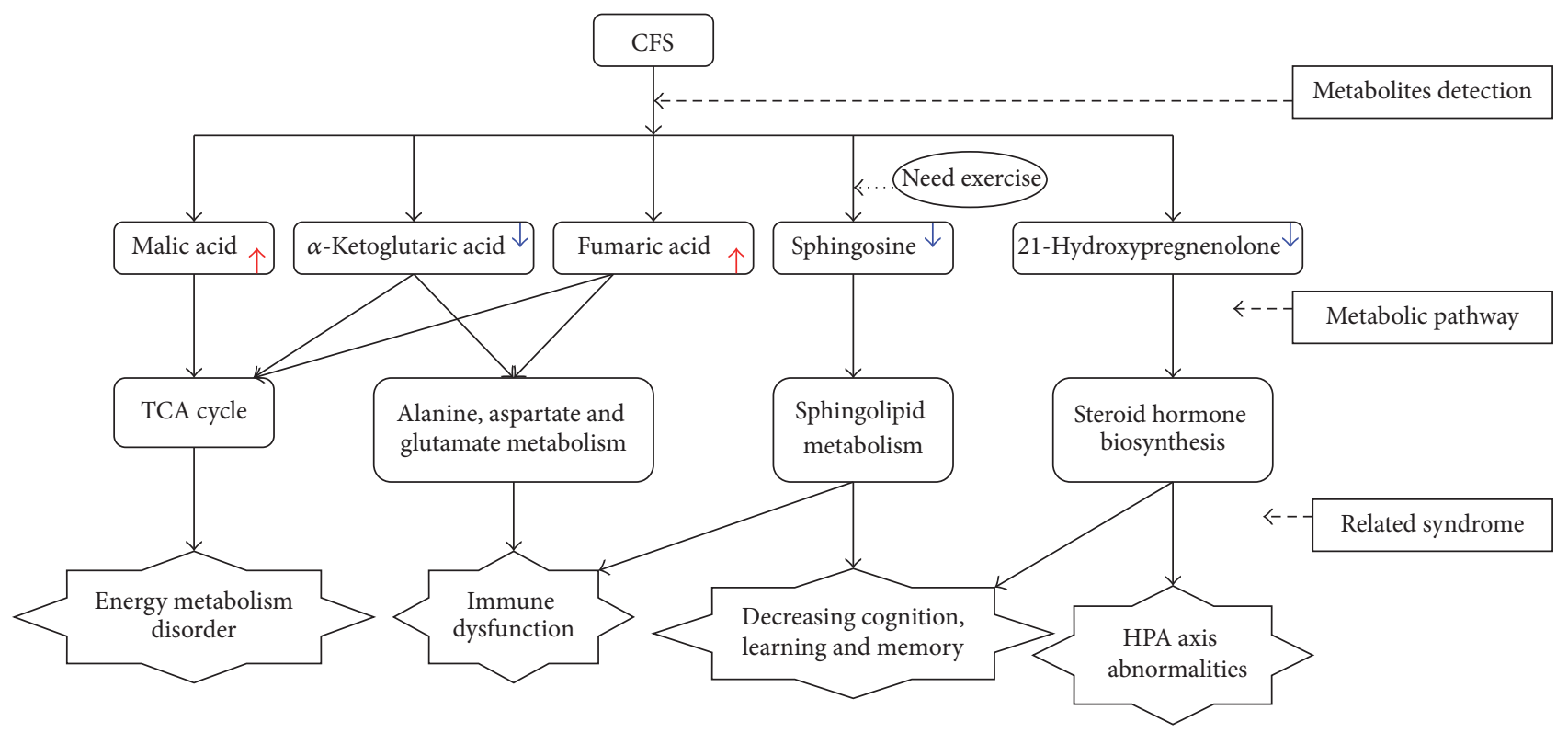

FIGURE 9: Metabolic mechanisms of CFS.

uncover additional metabonomic information regarding the development of the condition.

\section{Conflicts of Interest}

The authors declare that there are no conflicts of interest regarding the publication of this paper.

\section{Authors' Contributions}

Aiping Chi contributed to the conception and designed the metabonomics analysis. Changzhuan Shao collected the metabonomics data. Animal test was done by Yiming Ren and Zinan Wang. Chenzhe Kang performed the statistical analysis. Aiping Chi wrote the original thesis. 


\section{Acknowledgments}

This work was supported by the Humanities and Social Science project of Chinese Education Department (16YJA890001) and College Students' Innovative and Training project of Chinese Education Department (201610718068).

\section{References}

[1] C. G. Son, "A case of chronic fatigue syndrome improved by traditional Korean medicine," Integrative Medicine Research, vol. 2, no. 1, pp. 32-35, 2013.

[2] K. Fukuda, S. E. Straus, I. Hickie, M. C. Sharpe, J. G. Dobbins, and A. Komaroff, "The chronic fatigue syndrome: a comprehensive approach to its definition and study," Annals of Internal Medicine, vol. 121, no. 12, pp. 953-959, 1994.

[3] L. Steele, J. G. Dobbins, K. Fukuda et al., "The epidemiology of chronic fatigue in San Francisco," American Journal of Medicine, vol. 105, no. 3A, pp. 611-614, 1998.

[4] S. Wessely, T. Chalder, S. Hirsch, P. Wallace, and D. Wright, "The prevalence and morbidity of chronic fatigue and chronic fatigue syndrome: a prospective primary care study," American Journal of Public Health, vol. 87, no. 9, pp. 1449-1455, 1997.

[5] S. Lee, H. Yu, Y. Wing et al., "Psychiatric morbidity and illness experience of primary care patients with chronic fatigue in Hong Kong," The American Journal of Psychiatry, vol. 157, no. 3, pp. 380-384, 2000.

[6] X. Q. Wang, T. Takahashi, S. Zhu et al., "Effect of Hochu-ekkito (TJ-41), a Japanese herbal medicine, on daily activity in a murine model of chronic fatigue syndrome," Evidence-Based Complementary and Alternative Medicine, vol. 1, no. 2, pp. 203206, 2004.

[7] A. C. Logan and C. Wong, "Chronic fatigue syndrome: oxidative stress and dietary modifications," Alternative Medicine Review, vol. 6, no. 5, pp. 450-459, 2001.

[8] A. S. Papadopoulos and A. J. Cleare, "Hypothalamic-pituitaryadrenal axis dysfunction in chronic fatigue syndrome," Nature Reviews Endocrinology, vol. 8, no. 1, pp. 22-32, 2012.

[9] H. Rosenblum, Y. Shoenfeld, and H. Amital, "The common immunogenic etiology of chronic fatigue syndrome: from infections to vaccines via adjuvants to the ASIA syndrome," Infectious Disease Clinics of North America, vol. 25, no. 4, pp. 851-863, 2011.

[10] D. Wagner, R. Nisenbaum, C. Heim, J. F. Jones, E. R. Unger, and W. C. Reeves, "Psychometric properties of the CDC symptom inventory for assessment of chronic fatigue syndrome," Population Health Metrics, vol. 3, article 8, 2005.

[11] N. Guo, D. Yang, X. Wang, J. Dai, M. Wang, and Y. Lei, "Metabonomic study of chronic heart failure and effects of Chinese herbal decoction in rats," Journal of Chromatography A, vol. 1362, pp. 89-101, 2014.

[12] Y. Hua, W. Xue, M. Zhang, Y. Wei, and P. Ji, "Metabonomics study on the hepatoprotective effect of polysaccharides from different preparations of Angelica sinensis," Journal of Ethnopharmacology, vol. 151, no. 3, pp. 1090-1099, 2014.

[13] V. Lalremruta and G. S. Prasanna, "Evaluation of protective effect of Aegle marmelos Corr. in an animal model of chronic fatigue syndrome," Indian Journal of Pharmacology, vol. 44, no. 3, pp. 351-356, 2012.

[14] A. K. Sachdeva, A. Kuhad, and K. Chopra, "Epigallocatechin gallate ameliorates behavioral and biochemical deficits in rat model of load-induced chronic fatigue syndrome," Brain Research Bulletin, vol. 86, no. 3-4, pp. 165-172, 2011.

[15] T. Takahashi, F. Yu, S.-J. Zhu et al., "Beneficial effect of Brewers' yeast extract on daily activity in a murine model of chronic fatigue syndrome," Evidence-Based Complementary and Alternative Medicine, vol. 3, no. 1, pp. 109-115, 2006.

[16] A. Chi, C. Kang, Y. Zhang et al., "Immunomodulating and antioxidant effects of polysaccharide conjugates from the fruits of Ziziphus Jujube on Chronic Fatigue Syndrome rats," Carbohydrate Polymers, vol. 122, pp. 189-196, 2015.

[17] A.-P. Chi, J.-P. Chen, Z.-Z. Wang, Z.-Y. Xiong, and Q.-X. Li, "Morphological and structural characterization of a polysaccharide from Gynostemma pentaphyllum Makino and its antiexercise fatigue activity," Carbohydrate Polymers, vol. 74, no. 4, pp. 868-874, 2008.

[18] D. B. Cook, G. Lange, J. Deluca, and B. H. Natelson, "Relationship of brain MRI abnormalities and physical functional status in chronic fatigue syndrome," International Journal of Neuroscience, vol. 107, no. 1-2, pp. 1-6, 2001.

[19] M. J. Heins, H. Knoop, and G. Bleijenberg, "The role of the therapeutic relationship in cognitive behaviour therapy for chronic fatigue syndrome," Behaviour Research and Therapy, vol. 51, no. 7, pp. 368-376, 2013.

[20] M. J. Heins, H. Knoop, J. Lobbestael, and G. Bleijenberg, "Childhood maltreatment and the response to cognitive behavior therapy for chronic fatigue syndrome," Journal of Psychosomatic Research, vol. 71, no. 6, pp. 404-410, 2011.

[21] C. C. Gandhi, R. M. Kelly, R. G. Wiley, and T. J. Walsh, "Impaired acquisition of a Morris water maze task following selective destruction of cerebellar purkinje cells with OX7saporin," Behavioural Brain Research, vol. 109, no. 1, pp. 37-47, 2000.

[22] B. Evengård, R. S. Schacterle, and A. L. Komaroff, "Chronic fatigue syndrome: new insights and old ignorance," Journal of Internal Medicine, vol. 246, no. 5, pp. 455-469, 1999.

[23] S. P. Van der Werf, J. B. Prins, J. H. M. M. Vercoulen, J. W. M. Van der Meer, and G. Bleijenberg, "Identifying physical activity patterns in chronic fatigue syndrome using actigraphic assessment," Journal of Psychosomatic Research, vol. 49, no. 5, pp. 373379, 2000.

[24] K. K. McCully and B. H. Natelson, "Impaired oxygen delivery to muscle in chronic fatigue syndrome," Clinical Science, vol. 97, no. 5, pp. 603-608, 1999.

[25] D. Buchwald and A. L. Komaroff, "Review of laboratory findings for patients with chronic fatigue syndrome," Reviews of Infectious Diseases, vol. 13, pp. S12-S18, 1991.

[26] S. V. Kamzolova, N. V. Shishkanova, I. G. Morgunov, and T. V. Finogenova, "Oxygen requirements for growth and citric acid production of Yarrowia lipolytica," FEMS Yeast Research, vol. 3, no. 2, pp. 217-222, 2003.

[27] C. M. Pariante, "Chronic fatigue syndrome and the immune system: 'findings in search of meanings", Brain, Behavior, and Immunity, vol. 23, no. 3, pp. 325-326, 2009.

[28] H. Prinsen, I. J. M. de Vries, R. Torensma et al., "Humoral and cellular immune responses after influenza vaccination in patients with chronic fatigue syndrome," BMC Immunology, vol. 13, article 71, 2012.

[29] E. W. Brenu, K. J. Ashton, M. Van Driel et al., "Cytotoxic lymphocyte microRNAs as prospective biomarkers for Chronic Fatigue Syndrome/Myalgic Encephalomyelitis," Journal of Affective Disorders, vol. 141, no. 2-3, pp. 261-269, 2012. 
[30] M. A. Fletcher, K. J. Maher, and N. G. Klimas, "Natural killer cell function in chronic fatigue syndrome," Clinical and Applied Immunology Reviews, vol. 2, no. 2, pp. 129-139, 2002.

[31] J. Zou, J. Yuan, S. Lv, and J. Tu, "Effects of exercise on behavior and peripheral blood lymphocyte apoptosis in a rat model of chronic fatigue syndrome," Journal of Huazhong University of Science and Technology-Medical Science, vol. 30, no. 2, pp. 258264, 2010.

[32] P. Newsholme, K. Bender, A. Kiely, and L. Brennan, "Amino acid metabolism, insulin secretion and diabetes," Biochemical Society Transactions, vol. 35, no. 5, pp. 1180-1186, 2007.

[33] P. De Becker, N. McGregor, and K. De Meirleir, "Possible triggers and mode of onset of chronic fatigue syndrome," Journal of Chronic Fatigue Syndrome, vol. 10, no. 2, pp. 3-18, 2002.

[34] C. Heim, D. Wagner, E. Maloney et al., "Early adverse experience and risk for chronic fatigue syndrome: results from a population-based study," Archives of General Psychiatry, vol. 63, no. 11, pp. 1258-1266, 2006.

[35] N. G. Klimas and A. O. Koneru, "Chronic fatigue syndrome: inflammation, immune function, and neuroendocrine interactions," Current Rheumatology Reports, vol. 9, no. 6, pp. 482-487, 2007.

[36] A. T. White, A. R. Light, R. W. Hughen, T. A. Vanhaitsma, and K. C. Light, "Differences in metabolite-detecting, adrenergic, and immune gene expression after moderate exercise in patients with chronic fatigue syndrome, patients with multiple sclerosis, and healthy controls," Psychosomatic Medicine, vol. 74, no. 1, pp. 46-54, 2012.

[37] A. González-Usano, O. Cauli, A. Agusti, and V. Felipo, "Pregnenolone sulfate restores the glutamate-nitric-oxide-cGMP pathway and extracellular GABA in cerebellum and learning and motor coordination in hyperammonemic rats," ACS Chemical Neuroscience, vol. 5, no. 2, pp. 100-105, 2014.

[38] A. Kreinin, N. Bawakny, and M. S. Ritsner, "Adjunctive pregnenolone ameliorates the cognitive deficits in recent-onset schizophrenia," Clinical Schizophrenia \& Related Psychoses, vol. 1, no. 1, pp. 25-31, 2014.

[39] R. Wheatland, "Chronic ACTH autoantibodies are a significant pathological factor in the disruption of the hypothalamicpituitary-adrenal axis in chronic fatigue syndrome, anorexia nervosa and major depression," Medical Hypotheses, vol. 65, no. 2, pp. 287-295, 2005.

[40] N. J. Haughey, V. V. R. Bandaru, M. Bae, and M. P. Mattson, "Roles for dysfunctional sphingolipid metabolism in Alzheimer's disease neuropathogenesis," Biochimica et Biophysica Acta (BBA)_Molecular and Cell Biology of Lipids, vol. 1801, no. 8, pp. 878-886, 2010.

[41] K. Iwata, H. Matsuzaki, T. Miyachi et al., "Investigation of the serum levels of anterior pituitary hormones in male children with autism," Molecular Autism, vol. 2, no. 1, article 16, 2011.

[42] C. Bode and M. H. Gräler, "Immune regulation by sphingosine 1-phosphate and its receptors," Archivum Immunologiae et Therapiae Experimentalis, vol. 60, no. 1, pp. 3-12, 2012.

[43] A. J. Melendez, "Sphingosine kinase signalling in immune cells: potential as novel therapeutic targets," Biochimica et Biophysica Acta, vol. 1784, no. 1, pp. 66-75, 2008.

[44] A. Cheshire, D. Ridge, L. Clark, and P. White, "Why patients with Chronic Fatigue Syndrome/Myalgic Encephalomyelitis improve or deteriorate with graded exercise therapy," Journal of Psychosomatic Research, vol. 85, p. 59, 2016. 

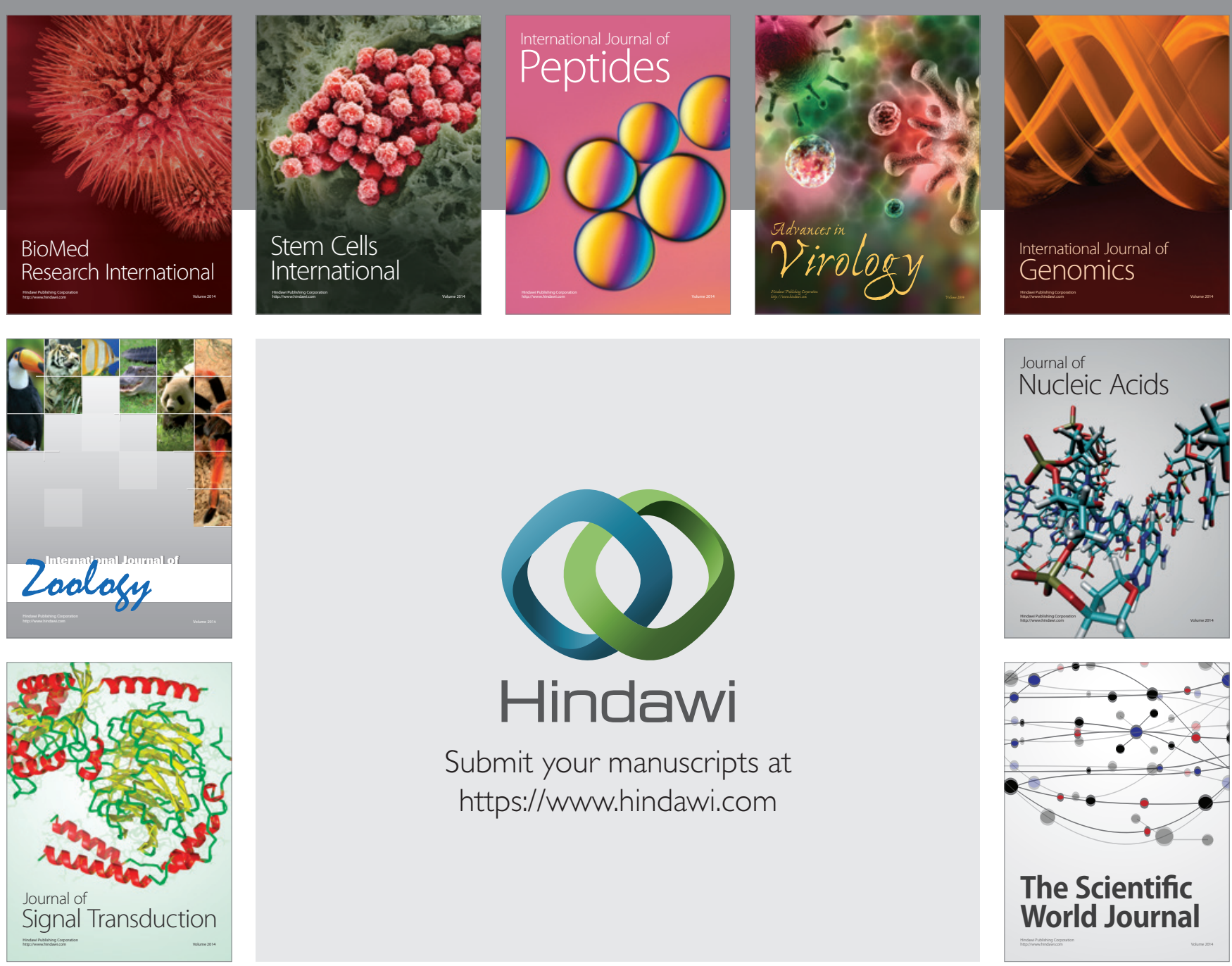

Submit your manuscripts at

https://www.hindawi.com
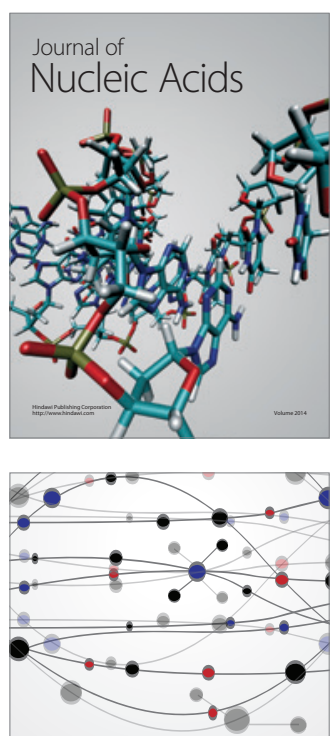

The Scientific World Journal
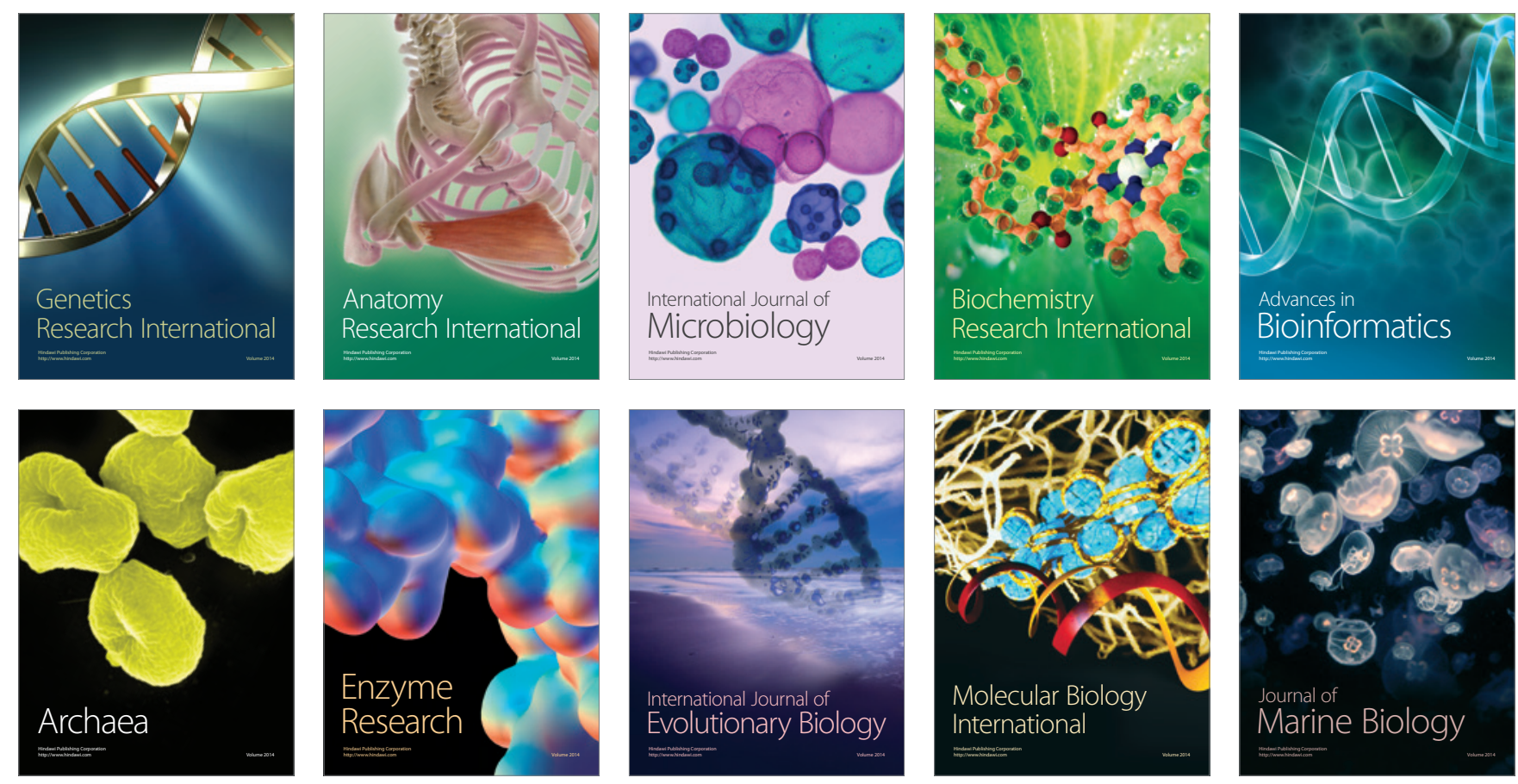